\title{
As concepções de "território" na pesquisa histórica: o sertão paulista
}

\author{
[ The meanings of "territory" in historical research: São Paulo's hinterland
}

\section{Amália Cristovão dos Santos ${ }^{\mathrm{I}}$}

RESUMO - Sendo o território a transformação do espaço segundo uma lógica específica - oficial, econômica, militar ou outra -, são várias as possibilidades de apreensão desse processo, criando diferentes significados. No presente artigo, apontamos quatro deles: a demarcação oficial de fronteiras; a representação institucional no espaço; os caminhos que unem e questionam os limites definidos; e a ideia de rede urbana. Para cada um, apontamos pesquisadores e as conceituações que constroem na esfera de seus trabalhos. Essa análise faz parte das reflexões que ensejamos em nossa pesquisa de doutorado em andamento, na qual examinamos as dinâmicas internas da colônia e a forma como formavam e conformavam o território, especificamente o sertão paulista. - PALAVRAS-CHAVE - território, história colonial, São Paulo, sertão, rede urbana - ABSTRACT - Considering the territory to be the transforming of a space according to an specific logic - official, economic, military, or other - there are innumerous possibilities of comprehension of this process, creating different meanings to this word. The following article presents four them: the official definition of the borders; the local representation of the administrative institutions; the routes that connect and question the defined limits; and the idea of an urban network. For every definition, we point out researchers and analyze particular works in which they undertake such conceptualization. This analysis is part of the considerations of our own ongoing research, in which we examine the activities that took place in the countryside of the colony, and the ways through which they configured the territory, specifically São Paulo's hinterland. · KEYWORDS - territory, colonial history, São Paulo, hinterland, urban network

Recebido em 05 de junho de 2014

Aprovado em $2 \mathrm{I}$ de novembro de 2014

DOI: http://dx.doi.org/Io.II606/issn.23I6-90IX.voi63pI8I-20I

I Universidade de São Paulo (USP, São Paulo, SP, Brasil). 


\section{INTRODUÇÃO'}

A pesquisa histórica como um todo e - em especial - os estudos sobre a ocupação do espaço colonial lidam com o território e a evolução de seu povoamento. Nesses trabalhos, a própria definição de "território" é parte de suas reflexões pois explicita a forma como entende-se a relação entre fatos históricos, instituições, atividades e o espaço por eles mobilizado. De modo geral, podemos dizer que território é uma porção de espaço transformada por um vetor - em que se somam e articulam atividades, ações, planos, população e materialidades.

No universo dos estudos históricos da São Paulo colonial, encontramos, entre outras, duas formas de abordagem do desenvolvimento da ocupação da capitania paulista que podem ser tomadas como opostas no que diz respeito à configuração do território. De um lado, temos os estudos que argumentam sobre a linearidade desse processo, tendo a agroexportação cafeeira como ponto de ruptura, a partir do qual a capitania teria ganhado força econômica real. ${ }^{3}$ De outro, temos as pesquisas que constroem a ideia de que a capitania teria se desenvolvido em meio a um povoamento configurado por movimentos pulsantes de ocupação dos sertões coloniais, que têm a vila de São Paulo como peça-chave.

Trata-se marcadamente do conceito de "equilíbrio vital",4 segundo o qual a ocupação do interior da colônia pelos paulistas teria sido realizada em ações pendulares, de intensidade e duração variáveis. Sérgio Buarque de Holanda analisa

2 Esse artigo é parte das atividades de pesquisa realizadas atualmente com o financiamento da Fapesp. Indispensável agradecer as considerações dos pareceristas da Revista do IEB sobre o artigo original, substancialmente menor, no que diz respeito à profundidade do debate proposto.

3 Ver: PRADO, Paulo. Paulística etc. São Paulo: Cia. das Letras, 2004; BRUNO, Hernani da Silva. História e tradições da cidade de São Paulo: Volume I - Arraial de Sertanistas (I554-I828). São Paulo: Editora Hucitec, I99I; MONBEIG, Pierre. Formação Histórica de São Paulo: de comunidade a metrópole. Tradução dos acréscimos Antonio Candido e Maria Sylvia Carvalho Moreira. São Paulo: Difel, I970; VILLA, Marco Antonio. Breve história do Estado de São Paulo. São Paulo: Imprensa Oficial, 2010.

4 HOLANDA, Sérgio Buarque de. “Movimentos da população em São Paulo no século XVIII”. Revista do Instituto de Estudos Brasileiros, São Paulo, v. I, p. 55-III, I966. 
o desenvolvimento da capitania a partir da relação entre a ocupação do espaço ao longo do tempo e as atividades econômicas realizadas em diferentes períodos e, por vezes, em sobreposição. A própria retomada dessa ideia, feita por Ilana Blaj por meio do uso do conceito de "movimento", já sugere uma relação entre as ações e o espaço.

$\mathrm{Na}$ pesquisa de doutorado que conduzimos no presente, analisamos a rede de relações econômicas, militares e de comunicações no interior da colônia, que tem a cidade de São Paulo como localidade central na organização dessas atividades e no cruzamento de rotas, que ligam: nordeste açucareiro, receptor de gado; fronteiras em definição entre Brasil e América espanhola, na Bacia do Prata; regiões de exploração de ouro e metais preciosos, em Mato Grosso, Goiás e Minas Gerais; estradas para portos e praças comerciais de Santos e Rio de Janeiro; engenhos açucareiros no oeste paulista; e a própria sede da capitania e seus arredores. Em nosso trabalho, essa rede é reconstituída como parte das ações que possibilitam, ao longo do século XVIII, a construção de uma imagem de domínio quase total dos portugueses sobre uma vasta região do interior do continente, dando embasamento às negociações diplomáticas que redefinem as fronteiras entre as possessões americanas das Coroas ibéricas.

O processo de conceituação do espaço - tendo como objeto a definição de "território" - é parte central do estudo que conduzimos, para o quê foi preciso analisar a forma como essa categoria foi mobilizada pela historiografia brasileira, em especial nos trabalhos relativos à história urbana.$^{6}$ Apontaremos, pois, no corpo deste artigo, quatro esferas principais de compreensão, tomadas como campos de referência da delimitação territorial, presentes em obras e estudos datados desde o início do século XX até o presente. Essas esferas não são estanques, tampouco são assim mobilizadas nos trabalhos que analisaremos adiante, ainda que existam aproximações e distanciamentos em relação a essas possibilidades de conceituação. Por fim, proporemos, a partir de nosso trabalho, uma outra esfera, pela qual circulam todas as demais.

A atribuição do significado de "território" não é o objeto central de nenhum dos estudos arrolados, mas perpassa a formação do arcabouço conceitual e metodológico de todos, sendo portanto uma definição que se mostra indispensável para esses trabalhos. Reconhecendo essa importância, esboçamos a seguir um panorama da definição de "território", dentro do escopo proposto, buscando explicitar e fortalecer o papel central desse conceito para os estudos de história urbana em geral.

\section{OS MAPAS E A DEMARCAÇão DO TERRITÓRIO OFICIAL}

A cartografia histórica é um campo primordial para investigações acerca da ocupação do espaço e suas definições. Destacamos aqui os trabalhos que vêm investigando aspectos variados da produção, comercialização e utilização dos mapas

5 BLAJ, Ilana. A trama das tensões: o processo de mercantilização de São Paulo colonial (I68I-I72I). São Paulo: Humanitas; Fapesp, 2002, p. 70 [grifos nossos].

6 Entendemos por “urbanização" todo o desenvolvimento de aglomerações populacionais no período colonial brasileiro: cidades, vilas, freguesias, arraiais e povoados em geral. 
confeccionados durante o período colonial. Um desses aspectos é o emprego da cartografia como recurso para a solução de conflitos na demarcação das fronteiras entre as Américas portuguesa e espanhola - interpretação que remonta aos trabalhos de Jaime Cortesão, em especial aos escritos no decorrer de suas atividades letivas no Ministério das Relações Exteriores do Brasil, entre I944 e I950.

Analisando o papel central do negociador português Alexandre de Gusmão no estabelecimento do Tratado de Madrid (I750), Cortesão faz uma descrição esquemática do documento em que constava a primeira proposta de definição das fronteiras coloniais dessa negociação, o Tratado de Limites entre Portugal e Espanha na América do Sul, de I748. Na recapitulação dos principais tópicos, o autor assinala que as Coroas ibéricas abriram mão da demarcação dos limites do Tratado de Tordesilhas, em vigor desde I494, por se tratar de uma linha por demais abstrata. Enfrentando essa questão, a nova proposta previa a articulação da posse por direito com a configuração "natural" das terras, conservando, dentro dos limites possíveis, "a posse e ocupação atual, e escolher em toda a parte, onde a situação o permitir, as balisas naturais de montes e rios"?

Em vez de um meridiano imposto pela geometria, irreal e que descurava as características dos espaços que dividia, definiram-se então limites que tinham como referência as 'balizas naturais', isto é, os rios, as serras e as cumeadas dos montes. ${ }^{8}$

Demarcando aspectos identificáveis do espaço, transferia-se o desenho das fronteiras, da representação cartográfica para a situação física, dificultando questionamentos futuros e naturalizando o traçado. Tomamos aqui o conceito de "naturalização" tal como apontando pela geógrafa Gisele Girardi, a partir das interpretações, feitas nas últimas décadas, da cartografia como linguagem. Em suas palavras, o mapa como representação carrega consigo um elemento de "precisão", que se traduz em "verdade", transformando seu conteúdo em mito, ou em "uma mensagem que visa à naturalização da cultura".

Diz Cortesão que "A parte essencial do Tratado, a que havia de perdurar como revelação dum organismo geográfico e político, até aí desconhecido ou apenas entrevisto, já aparece em sua pujante grandeza, no projeto". ${ }^{\text {ro }} \mathrm{E}$, portanto, justamente desse dispositivo de mitificação que Gusmão vai tomar partido ao adiantar-se à Coroa

7 CORTESÃO, Jaime. Alexandre de Gusmão eło Tratado de Madrid, tomo 2. São Paulo: Imprensa Oficial; Fundação Alexandre de Gusmão, 2006, p. 320 [grifos nossos].

8 FERREIRA, Mário Clemente. Os demarcadores do Tratado de Madrid (7750) e as reformas pombalinas de ensino. In: IV SIMPÓSIO LUSOBRASILEIRO DE CARTOGRAFIA HISTÓRICA, 20II, Porto. Anais do IV Simpósio.... Porto: Faculdade de Letras da Universidade do Porto, 20II, p. I-II, p. I-2.

9 GIRARDI, Gisele. Leitura de mitos em mapas. Geografares, Vitória, v. I, n. I, p. 4I-50, jun., 2000, p. 7.

IO CORTESÃO, op. cit., p. 325 . 
espanhola na feitura de um mapa - valendo-se de deformações de representação ${ }^{\mathrm{II}}$-, que logo sobreporia a imagem grandiosa do triângulo invertido que se estende para o interior do continente àquela do Brasil como território selvagem, agarrado ao mar.

Vários foram os documentos usados como fontes para as definições do Tratado de Madrid: relatos, relatórios oficiais, cartas parciais, material levantado para essa tarefa específica ou não. Os mapas tiveram função central nessa empreitada, por "serem uma simplificação da informação sobre uma determinada região". Enumerando os usos e desusos de fontes cartográficas, Mario Clemente Ferreira faz referências aos mapas como uma produção seriada de desenhos, de autoria coletiva e processual, não apenas copiado sistematicamente, mas modificado ou passível de modificação a cada novo trabalho. ${ }^{\mathrm{I2}}$

Ainda que o mapa fosse executado por apenas um indivíduo, os levantamentos que informariam seu conteúdo eram resultado do trabalho de muitos - às vezes até mesmo feitos para outros fins -, de modo que a autoria não pode ser a atribuição de um nome a um conjunto de traços e, se assim for, não nos interessa no âmbito da pesquisa histórica. Engenheiros militares, padres matemáticos, cartógrafos, viajantes, nativos, exploradores, desenhistas, editores, negociantes e diplomatas - sem relevar a figura do rei - compunham a rede de circulação que fez possível um domínio superior dos portugueses sobre o espaço conhecido e representado, definindo-se assim as linhas de fronteira.

No contexto das disputas entre as duas Coroas ibéricas, a demarcação oficial dos limites fronteiriços era, portanto, indispensável enquanto estratégia de consolidação do território. No artigo "Cartografia e diplomacia: usos geopolíticos da informação toponímica (I750-I850)", Iris Kantor apresenta a sucessão de acordos diplomáticos definidores da posse da terra que incidiam sobre a América, destacando "a dimensão jurídica e diplomática evocada pelo uso dos topônimos nas negociações diplomáticas internacionais desde meados do século XVII". ${ }^{\text {I3 }}$ Para a assinatura do Tratado de Madrid,

Os demarcadores e os governadores foram instruídos a renomear os acidentes geográficos, as vilas e os aldeamentos jesuíticos de origem espanhola encontrados em seus percursos. Visavam a erradicar a toponímia missionária para fixar o uti possidetis lusitano. ${ }^{\text {I4 }}$

Em outras palavras: buscavam forjar uma representação de domínio dos

II Cortesão compara o Mapa das Cortes, síntese espacial do Tratado de Madrid, ao Mapa da América do Sul, de D'Anville, impresso com data de I748, para afirmar que a soma dos erros contidos no risco projetado por Gusmão era resultado de operação intencional, a fim de amenizar a grandiosidade do território proposto para Portugal. Ibid., p. 329-333.

I2 FERREIRA, op. cit., p. 53 .

I3 KANTOR, Iris. Cartografia e diplomacia: usos geopolíticos da informação toponímica (I750-I850). Anais do Museu Paulista, São Paulo, v. I7, n. 2, p. 39-6I, jul./dez., 2009, p. 40. Disponível em: <http://www.scielo.br/pdf/ anaismp/vI7n2/04.pdf >. Acesso em: 6 Ago. 2013.

I4 Ibid., p. 44 . 
portugueses sobre as áreas em contestação. A produção de uma cartografia que servisse aos interesses da Coroa era garantida pela redação e uso de material que instruía cartógrafos e engenheiros militares com relação ao levantamento territorial e à feitura dos mapas. Era imprescindível que o desenhista registrasse e representasse adequadamente "os montes, os outeiros, ou emminencias do terreno, os valles, os arvoredos, as vinhas, as hortas, os casaes, que houver, os caminhos, as quebradas, as ravinas, as pedreiras, os moinhos de agoa, ou de vento, as terras lavradas", ${ }^{5}$ num expediente coeso com a necessidade de fixação das fronteiras no espaço colonial, como indicado por Cortesão e Ferreira.

Um dos princípios centrais que regiam essa política era o fortalecimento do poder da metrópole, representado pelo reforço da estrutura administrativa na colônia e pela arregimentação da população em povoados organizados e reconhecidos dentro da hierarquia oficial. Portanto, para a demarcação desse território - espaço de posse da Coroa portuguesa, assim reconhecido pelos demais reinos -, era imprescindível a configuração jurídica e material de elementos que representassem essa ocupação, para além da representação oficial em documentações textuais e, principalmente, cartográficas.

\section{AS INSTITUIÇÕES E A SAGRAÇÃO DO ESPAÇO}

Outra faceta da história administrativa da colônia é o estudo da implementação das estruturas do poder oficial para o domínio do espaço, tema caro aos estudiosos que se debruçam sobre a administração do império português, desde o reino até as colônias. Figura central dessa vertente de pesquisa é Charles R. Boxer, que insere os estudos sobre o Brasil colonial num enquadramento global e comparativo sobre os domínios lusos - tema até então pouco explorado na historiografia brasileira. ${ }^{16}$ Um de seus capítulos é dedicado às câmaras municipais e às Santas Casas de Misericórdia, que "garantiam uma continuidade que os governadores, os bispos e os magistrados transitórios não podiam assegurar" ${ }^{17}$

Considerando a vastidão do império português, a distância era um elemento a ser levado em consideração, sobre o que afirma Boxer que "os obstáculos físicos, além de outros, à existência de comunicações eficientes deixavam, inevitavelmente, as câmaras com larga margem de autonomia”. ${ }^{\text {I8 }}$ Sendo essa constatação válida para as

I5 BUENO, Beatriz Piccolotto Siqueira. Decifrando mapas: sobre o conceito de "território" e suas vinculações com a cartografia. Anais do Museu Paulista, São Paulo, v. I2, p. I93-234, jan./dez., 2004, p. 24

I6 Ver: SOUZA, Laura de Mello e. "Política e administração colonial: problemas e perspectivas”. In: O Sol e a Sombra. São Paulo: Companhia das Letras, 2006, cap. I, p. 27-77.

I7 BOXER, Charles. O império marítimo português I4I5-I825. São Paulo: Companhia das Letras, 2002 [I969], p. 286.

I8 Ibid., p. 29I. 
vilas e cidades do reino, é de se supor que também o espaço colonial americano estava sujeito a tal condição. ${ }^{19}$

Laura de Mello e Souza examina a questão da distância e da possibilidade de influência das câmaras sobre as decisões reais a partir das aproximações e, principalmente, das diferenças entre as interpretações propostas por Raymundo Faoro e Caio Prado Jr. acerca do tema. Estão em jogo visões, de um lado, de uma expressividade total da mecânica de submissão da colônia à metrópole e, de outro, de uma ausência caótica que teria relegado os colonos ao improviso e à iniciativa própria. Nessa análise, a obra de Boxer e outros com a mesma preocupação, bem como trabalhos recentes, é vista na esteira da indispensabilidade da apreensão do Brasil como parte da vertente do império português no Atlântico sul, "conectando histórias espacialmente distintas". ${ }^{\circ}$ Para tal, um "aspecto fundamental" eram "as lógicas próprias do sistema administrativo do Império [português]”. ${ }^{2 \mathrm{I}}$

Um trabalho de fôlego e de esforço constante no sentido de apreender essas lógicas e de revisar a relação entre a metrópole portuguesa e sua colônia americana tem sido realizado pelos pesquisadores do grupo Antigo Regime nos Trópicos (ART). É indispensável apontar que os trabalhos do grupo e de Laura de Mello e Souza, ainda que direcionem o olhar para os mesmos pontos, podem ser colocados declaradamente em lados opostos da produção mais recente sobre o tema.

Os membros do ART realizam exaustivo trabalho sobre fontes pouco exploradas ou inéditas, orientando-se para o reposicionamento histórico de grupos antes considerados menos relevantes, periféricos ou marginais - como comerciantes de grosso trato, mamelucos, escravos e forros. Para esses pesquisadores, as microdinâmicas e as relações entre os variados grupos componentes da sociedade portuguesa - em que se incluem aqueles residentes permanente ou temporariamente nas colônias - teriam subvertido a lógica do poder irradiado do reino e que chegaria às demais porções do império de forma unidirecional, colocando as colônias em posição irrevogável de meros acessórios da metrópole.

Em crítica à publicação conjunta inaugural do grupo, $O$ antigo regime nos trópicos, Souza constata o que acredita ser uma ênfase exagerada no "poder local, [n] as redes clientelares, [n]os arranjos informais, [...] [n]a capacidade de negociação direta com a Corte”, ${ }^{22}$ que acaba por descartar quase por completo a presença do Estado

I9 É o que se pode ver, por exemplo, nas alterações em relação às formas de agremiação dos oficiais mecânicos na colônia e no reino. Ver: SANTOS, Amália Cristóvão dos. Em obras: os trabalhadores da cidade de São Paulo entre I775 e I809. São Paulo: Alameda, 2015 [no prelo].

20 SOUZA, op. cit., p. 42. Cabe aqui ressaltar o papel dos mapas também na naturalização de uma separação entre o Brasil e as possessões portuguesas em outros continentes. A ausência de uma cartografia mais divulgada em que conste a totalidade do império, representado como uma unidade, reforça a separação espacial e favorece o destrinchar dessa história comum em histórias "nacionais".

2I Ibid., p. 45.

22 Ibid., p. 58 
português. É reconhecendo tal precaução que analisaremos a seguir o conceito de "rede governativa", tal como formulado por Maria de Fátima Gouvêa. ${ }^{23}$

Dentro dos objetivos do presente artigo, mais precisamente com relação a este item, a argumentação de Gouvêa nos é relevante ao apontar que "segundo Ciro Cardoso, era fundamental também considerar as características do território colonial na conformação da organização material das sociedades coloniais" ${ }^{24} \mathrm{O}$ que isso indica é a necessidade de ir além dos estudos sobre a função original das câmaras e examiná-las a partir da relação dialética que estabelecem com o espaço, político e físico, em que se inserem. A ereção de casas de câmara e cadeia marcava o domínio do Estado português, ao mesmo tempo em que reconhecia a relevância daquela localidade ou região e de sua população para os interesses da Coroa, sem excluir, entretanto, suas relações hierárquicas, como destacou Laura de Mello e Souza.

De acordo com Gouvêa, "[...] uma rede é compreendida como um conjunto de conexões recorrentes, capazes de alterar ou definir estratégias, bem como o curso dos acontecimentos num dado lugar e época”. ${ }^{25}$ No entanto, esse conceito, da forma como exposto, pode suscitar uma imagem de horizontalidade dessas conexões, algo que a própria autora relativiza ao analisar a figura do rei: "Interdependência era a marca mais distintiva desse processo na medida em que equilíbrios instáveis dependiam de uma permanente harmonização das tensões e alianças. $\mathrm{O}$ rei era a cabeça desse corpo, desse equilíbrio social”. ${ }^{26}$

A concessão pelo rei de "honras e mercês" aos súditos era prática corrente da monarquia portuguesa e pode ser divisada, no espaço colonial americano, desde a definição das capitanias hereditárias. Tratava-se de uma compensação dada pela Coroa em reconhecimento da "iniciativa particular de seus vassalos ao longo do processo de colonização das chamadas partes do Brasil”. ${ }^{27}$ Esse mecanismo pode ser considerado parte da interdependência mencionada por Maria de Fátima Gouvêa, haja vista a indispensabilidade do braço particular para garantir a efetiva transformação do espaço colonial português em território do império, especialmente nos primeiros séculos da colonização.

A Coroa precisava dos colonos, e esses almejavam o reconhecimento de seus

23 No artigo em questão, a autora rebate especificamente as afirmações de Laura de Mello e Souza, partindo das obras de Jacob Gorender e Ciro Flamarion Santana Cardoso, desde a década de I970, seguidas por trabalhos que abarcaram as "dinâmicas internas dos conglomerados imperiais da Época Moderna”. GOUVÊA, Maria de Fátima Silva. "Redes governativas portuguesas e centralidades régias no mundo português, c. I680-I730". In: FRAGOSO, João; GOUVÊA, Maria de Fátima Silva. Na trama das redes: política e negócios no império português, séculos XVI-XVIII. Rio de Janeiro: Civilização Brasileira, 20IO, p. I55-202, p. I59-I63.

24 Ibid., p. I59. Entendemos o uso do termo "território" no referido trecho como referência às distâncias e especificidades do espaço físico e dos grupos populacionais presentes.

25 Ibid., p. I69.

26 Ibid., p. 166.

27 RICUPERO, Rodrigo. "Poder e patrimônio: o controle da administração colonial sobre as terras e a mão-de-obra indígena”. In: BICALHO, Maria Fernanda; FURTADO, Júnia Ferreiraa; SOUZA, Laura de Mello e. $O$ governo dos povos. São Paulo: Alameda, 2009, p. 355-370, p. 355. 
esforços - e o favorecimento que daí advinha. Esse procedimento, ao mesmo tempo em que fortalecia os poderes locais, reforçava a hierarquia real. Mas fica clara a relevância das configurações e empreendimentos específicos do espaço colonial, já que "as terras antes de serem doadas precisavam ser conquistadas". ${ }^{28}$ Essa sentença é particularmente relevante quando olhamos para a ocupação do sertão colonial e a para as imagens dicotômicas que são formadas sobre os paulistas, ora súditos leais a serviço da Coroa, ora desertores cuja única preocupação era o enriquecimento próprio. Independentemente do lado para que pese o julgamento, era reconhecido o domínio que tinham os paulistas sobre os confins coloniais e os chamados gentios que lá habitavam. ${ }^{29}$

Laura de Mello e Souza desenvolve sua argumentação sobre a questão por meio do exame de um conjunto de fontes e interpretações em que se destacam as habilidades de exploração, locomoção e guerra dos paulistas - muitas vezes equiparados aos indígenas nessas ações. Com o sucesso atingido pelas atividades resultantes das suas explorações, como a descoberta das minas de ouro, os paulistas passam a requerer mercês e reconhecimentos, por vezes inserindo-se oficialmente nos ramos da administração colonial ou apenas beneficiando-se dela.

Parte dos meandros dessa constante negociação pode ser apreendida pela própria investigação de Souza sobre a vida - vista através da morte - de Rodrigo César de Meneses, que foi governador de São Paulo e do Reino de Angola, na primeira metade do século XVIII..$^{\circ} \mathrm{Se}$, como governador de Angola era tido na mais alta estima pelos que viveram em seu tempo, não teve a mesma sorte com os memorialistas paulistas, em cujos escritos a autora identifica não apenas o ranço aos colonizadores mas também "a repulsa aos governantes portugueses de São Paulo, em geral, e a Rodrigo César, em particular, [que] se deve ao fato de ter estabelecido o aparelho do Estado, pondo fim ao período de liberdade e autonomia dos habitantes" ${ }^{3 \mathrm{I}} \mathrm{O}$ governador teria forçado, podemos dizer, a sedentarização dos heroicos bandeirantes.

"Onde não havia justiça nem governo, nas lonjeiras de um sertão quase deserto, a Coroa não tinha outra alternativa senão cortejar tais valentões [os paulistas].,"32 Trata-se de uma das lógicas da administração colonial: a necessidade de aliar-se, por vezes, àqueles cujas ações eram vistas como contrárias à dominação e à vassalagem. Em meio ao desenrolar dessa estratégia de minoração do poder local dos sertanistas, pretendida pelo governador Meneses, a divisão da capitania de São Paulo foi - mais do que uma preocupação com a demarcação das unidades territoriais - a implementação de um comando das áreas de mineração da forma mais independente possível da necessidade de negociação constante com os paulistas.

28 Ibid., p. 365.

29 SOUZA, Laura de Mello e. "São Paulo dos vícios e das virtudes". In: O Sol e a Sombra. Op. cit., p. I09-I47, p. II5-II6.

30 SOUZA, Laura de Mello e. “Morrer em colônias: Rodrigo César de Meneses, entre o mar e o sertão”. In: O Sol e a Sombra. Op. cit., p. 284-326.

3I Ibid., p. 293.

32 Ibid., p. 294. 
Analisando as câmaras coloniais como instituições municipais do poder português no ultramar, Vera Lucia Amaral Ferlini vai dizer: "No espaço colonial, as Câmaras adquiriram importância, na afirmação do poder real, marcada especialmente por seu papel de visibilidade das formas portuguesas de poder, nessa situação de distância”.33 Enquanto essa função não foi possível na totalidade do sertão colonial, podemos dizer que tal estratégia foi efetivamente materializada na ordenação do território das Minas Gerais.

Cláudia Damasceno Fonseca, ao pesquisar a formação da rede de vilas em função da exploração aurífera naquela região, 34 distingue expressamente o "sertão" do "território". O primeiro seria o espaço "virgem" de colonização enquanto o segundo é o espaço modificado, ocupado. A distinção de um estado para outro era gerada pela hierarquização de certos pontos: cidades, vilas, vilas cabeças de comarca, povoações-sede e arraiais. ${ }^{35}$ Esse território, portanto, constituiu-se pela implementação da estrutura administrativa da Coroa portuguesa numa terra considerada desocupada; é o fim de um espaço antes visto como homogêneo.

Por meio de fontes cartográficas, Fonseca analisa ainda os embates ocorridos em Minas Gerais na segunda metade do século XVIII, que mobilizavam arraiais, vilas e cidades, na disputa por demarcação e ampliação de seus limites oficiais. ${ }^{36}$ As medidas citadas pela autora correspondem à materialização, no espaço, das definições oficiais de limites e fronteiras em mapas - trata-se da demarcação propriamente dita e da representação física das instituições administrativas.

Sendo o período colonial um momento em que Igreja e Estado eram instituições atreladas no que diz respeito à regulamentação do modo de vida, é imprescindível nos atermos também à formação do patrimônio religioso, tal como propõe Murillo Marx, num processo em que as capelas eram responsáveis pela transposição das terras particulares para uma situação de coletividade. ${ }^{37}$ Essa transformação era feita "reconhecimento da sociedade organizada, por mais distante que estivessem os centros do poder" ${ }^{38}$

No entanto, ainda que a constituição da estrutura administrativa seja, não raro, um ponto de inflexão na configuração do território, os usos e a ocupação do espaço não correspondiam sempre aos limites jurídicos e fiscais impostos pelo poder

33 FERLINI, Vera Lúcia Amaral. "O município no Brasil colonial e a configuração do poder econômico". In: BICALHO, Maria Fernanda; FURTADO, Júnia Ferreiraa; SOUZA, Laura de Mello e, op. cit., p. 389-399, p. 390 [grifos nossos].

34 FONSECA, Cláudia Damasceno. Arraiais e vila d'El Rei: espaço e poder nas minas setecentistas. Belo Horizonte: Editora UFMG, 20II.

35 Ibid., p. 557.

36 FONSECA, Cláudia Damasceno. Retóricas cartográficas: as vilas e seus territórios nas Minas setecentistas. In: $3^{\circ}$ SIMPÓSIO IBEROAMERICANO DE HISTÓRIA DA CARTOGRAFIA - Agendas para História da Cartografia Iberoamericana, 20Io, São Paulo, p. 3. Disponível: <http://3siahc.files.wordpress.com/20Io/04/ claudia-damasceno-3siach-20Io.pdf >. Acesso em: I6 Jan. 20I4.

37 MARX, Murillo. Nosso chão: do sagrado ao profano. São Paulo: Editora da Universidade de São Paulo, I989. 38 Ibid., p. I8. 
público.39 Isso sugere que, ainda que essa forma de conceituação do território seja adequada aos estudos sobre a administração colonial no império português, podemos dizer que ela é insuficiente se levarmos em conta as atividades realizadas pela população, que ultrapassam as fronteiras administrativas, constituindo, podemos dizer, outro desenho do espaço.

\section{O TERRITÓRIO OFICIAL ATRAVESSADO}

Atividades tais como aquelas que analisamos em nosso doutorado, conforme descrito na Introdução, são empreendimentos que não se originam exclusivamente das determinações oficiais, tampouco restringem-se totalmente aos limites fronteiriços ou administrativos. Na esteira das revisões acerca da intensidade e das formas de atuação da administração colonial, levadas a cabo a partir da década de I970, ganham espaço os grupos populacionais e as atividades que não estavam diretamente relacionadas ao mercado eurocêntrico - mas que, em grande parte, mobilizavam e constituíam o sertão colonial.

O supracitado capítulo de Vera Lucia Ferlini concede-nos uma guisada privilegiada sobre as extensões - e os atravessamentos - territoriais dessas empreitadas. Passado o primeiro momento de restauração da capitania, os senadores das câmaras de São Paulo e outras solicitavam ao governador que proibisse, nas Minas Gerais, o plantio de tabaco e cana-de-açúcar e a produção de fumo e aguardente, medida que favoreceria as fazendas paulistas, por meio da cobrança de impostos sobre o trânsito de bens e escravos, e promoveria a adequada ocupação de suas terras. $4^{\circ}$

Essas cartas permitem entrever as relações e dependências entre os variados cultivos (de gêneros alimentícios ou matérias-primas), o tráfico de cativos, a criação e o trânsito de gado, a mineração e os diferentes ramos de comércio. No bojo das atividades mercantis das quais participavam os paulistas durante o período colonial, os limites territoriais oficializados não encerravam a extensão de suas ações: as estradas, rotas e caminhos diversos desenvolviam-se a partir de outra lógica, em que condições geográficas e a pré-existência de caminhos indígenas eram mais importantes que as disposições oficiais sobre o espaço.

Sobre a apropriação sucessiva de rotas, diz Sérgio Buarque de Holanda que a constituição original dos caminhos pode ser atribuída aos animais silvestres, sendo tomada sucessivamente por indígenas, por colonos e até mesmo pelos meios de transporte implantados no período imperial..$^{4} \mathrm{O}$ s caminhos percorridos pelos nativos foram construídos em período anterior à ocupação portuguesa e tinham como premissa principal a eficiência. O desenho do terreno suscitava, pois, possibilidades melhores e piores de trajetos, que se traduziam em potencial de uso para o comércio e as atividades extrativas.

Esse é o argumento central do artigo "O fator geográfico na formação e no

39 FONSECA, op. cit., p. 566.

40 FERLINI, op. cit., p. 396-399.

4 I HOLANDA, Sérgio Buarque de. Caminhos e Fronteiras. São Paulo: Cia. das Letras, I994, p. 26. 
desenvolvimento da cidade de São Paulo”, de Caio Prado Jr., publicado pela primeira vez em I935. Nesse momento, São Paulo era a segunda maior cidade do país, atrás apenas do Rio de Janeiro, e já tinha inquestionável importância econômica. Em vista disso, o autor busca justificar como a cidade superou o que considera percalços naturais para se tornar o "grande centro" que era..$^{42}$ A resposta estaria, para ele, em sua posição geográfica, que, mesmo com uma série de desvantagens, seria também a origem de seus desenvolvimentos: “o local de São Paulo é, sob vários aspectos, privilegiado. E é a isto que o maior centro do Estado deve sua situação e desenvolvimento".43 O sítio em que se encontra a cidade de São Paulo seria, para Prado Jr., predestinado ao sucesso.

É imprescindível notar que, diferentemente de Holanda, Caio Prado Jr. assume a importância das condições físicas como fator central no sucesso da ocupação da cidade de São Paulo, desprezando assim as disputas políticas, os interesses e os acontecimentos externos à cidade, que possibilitaram que sua população desfrutasse das vantagens do sítio. Faz-se necessário, portanto, ir além dos apontamentos de Prado Jr. - ainda que esses sejam precisos, no que diz respeito às condições geográficas da área. As condições da localização, no entanto, possibilitadores de um modo de vida em que as comunicações configuravam-se como um dos bens de maior valor para o desenvolvimento das atividades econômicas.

Ainda que insuficiente, como vimos anteriormente, a ideia da posição privilegiada ventilada por Caio Prado Jr. ressoa em trabalhos recentes, como em A teia mercantil, de Maria Aparecida de Menezes Borrego. ${ }^{44} \mathrm{Na}$ justificativa do recorte espacial de seu objeto de estudo, a autora afirma:

Sua localização [da cidade de São Paulo] era extremamente favorável ao desenvolvimento do comércio, pois se encontrava no centro de convergência de diversas rotas que ligavam a cidade às demais vilas paulistas, ao porto de Santos, a Curitiba, às áreas auríferas de Minas Gerais, Cuiabá e Goiás, e ao Rio de Janeiro. ${ }^{45}$

Ilana Blaj, em capítulo de título sugestivo, "As veredas da mercantilização”, ${ }^{46}$ distancia-se das interpretações deterministas acerca das vantagens geográficas do sítio, indicando a relação entre as ações produtivas e exploradoras e o uso e criação dos caminhos que se cruzavam na cidade de São Paulo. Se, por algum tempo, essas estradas - de chão e de rio - mobilizaram os exploradores do sertão colonial, em fins

\footnotetext{
42 PRADO Jr., Caio. O fator geográfico na formação e no desenvolvimento da cidade de São Paulo. In: Cidade de São Paulo: Geografia e História. São Paulo: Brasiliense, I989, p. 7.

43 Ibid., p. 8 [grifos nossos].

44 BORREGO, Maria Aparecida de Menezes. A teia mercantil: negócios e poderes em São Paulo colonial (I7II-I765). São Paulo: Alameda, 2010.

45 Ibid., p. 24.

46 BLAJ, op. cit., p. I57-208.
} 
do século XVII eram os comerciantes que atravessavam regiões, beneficiando-se dessas rotas, que integravam a vila a uma economia de mercado. 47

Em meio à consolidação, em extensa área, desse mercado interno, São Paulo procura "assumir uma posição hegemônica sobre os demais núcleos, fortalecendo-se em relação às outras vilas e povoados locais" ${ }^{38}$. A forma como Blaj argumenta sobre a centralidade da então vila dá peso ao processo de escolhas e estratégias que toma lugar durante certo período, em que os paulistas beneficiam-se das pretensões da Coroa para atingirem a posição desejada. O caráter de negociação e interdependência entre as elites locais e a administração colonial, tal como apontado pela autora, refuta qualquer ideia de predestinação do povo paulista ou de sua localização. Eram as dinâmicas internas integradoras a principal moeda de troca nessa disputa, dando a São Paulo hegemonia sobre diversas regiões da colônia, desde o litoral vicentino até os sertões. 49

Apesar do destaque que atingiram o comércio e as explorações auríferas nos estudos de história colonial, outras dinâmicas também devem ser salientadas, tais como aquelas relativas à criação e comércio de gado, cujos caminhos uniam desde os campos do sul até as fazendas do nordeste açucareiro, passando por São Paulo e pela feira de Sorocaba. Em tese sobre a criação das imagens de pobreza e riqueza, associadas respectivamente às capitanias de São Paulo e Pernambuco, ${ }^{50}$ Milena Maranho opera por meio de uma análise comparativa dos documentos coloniais e das historiografias produzidas sobre as duas áreas, apontando que, em I700, havia informações sobre a presença de "mais de cem casais todos Paulistas". ${ }^{5}$

Podemos, de certa forma, traçar as origens dessa vertente de estudo nos escritos de Capistrano de Abreu, que se propôs a examinar as dinâmicas internas da América portuguesa, descolando-se declaradamente das interpretações que cunhavam uma "história oficial", vinculada ao Instituto Histórico e Geográfico Brasileiro (IHGB).52 Abreu dispensou considerável atenção ao que definiu como "o povoamento do sertão, iniciado em épocas diversas, de pontos apartados, até formar-se uma corrente interior, mais volumosa e mais fertilizante que o tênue fio litorâneo".53

É desses movimentos de ocupação - que conjugam atividades, espaços, tempos e

\footnotetext{
47 Ibid., p. I68 [grifos nossos].

48 Ibid., p. 169.

49 Ibid., p. I66-208.

50 MARANHO, Milena Fernandes. O moinho e o engenho. 2006. Tese (Doutorado) - Faculdade de Filosofia, Letras e Ciências Humanas, Universidade de São Paulo, São Paulo, 2006.

5I Carta de Pedro Taques de Almeida, que foi capitão-mor das vilas de Santos e São Paulo para D. João de Lencastro, respondendo aos informes pedidos sobre o Estado, Sertão, Minhas de São Paulo e Quintos Reais. São Paulo, 20 de março de I700. Biblioteca d'Ajuda, códice 5I-IX-33, fls. 460-467, fl. 460. Apud MARANHO, op. cit., p. 342.

52 Ibid., p. 22-26.

53 ABREU, João Capistrano Honório de. Capítulos de História Colonial. Rio de Janeiro: Civilização Brasileira, I976, p. 98.
} 
populações - que trata o autor na maior porção de seus Capítulos de História Colonial, denominado, não por acaso, "Sertão".54 Em suma, Abreu refere-se a:

Os triunfos colhidos em guerras contra os estrangeiros, as proezas dos bandeirantes dentro e fora do país,55 a abundância de gados animando a imensidade dos sertões, as copiosas somas remetidas para o governo da metrópole, as numerosas fortunas, o acréscimo da população [...] [e os] descobertos auríferos..$^{56}$

O que se destaca nas interpretações supracitadas, em especial nos trabalhos recentes que trazem à luz cada atividade desenvolvida nos confins, é o reconhecimento da integração de diferentes áreas da colônia, no que os caminhos terrestres e fluviais são protagonistas. Para além da articulação de variados territórios, que rompem limites e fronteiras, podemos valer-nos do conceito de rede, não como forma de relação entre os habitantes dessas regiões, mas como relação mesma entre as regiões. Em outras palavras, as ligações regulares e sobrepostas são a trama que conforma, ao fim e ao cabo, um único território - ou um único espaço em que as comunicações são a lógica transformadora e constitutiva, como veremos a seguir.

\section{Pontos, Linhas E PLANOS: AS REDES}

Retomando as diversas enumerações de atividades intracoloniais, tal como expostas anteriormente, vemos que, para cada rota descrita pelos autores, há um movimento de exploração, ocupação e ligação, ao qual corresponde um período de tempo, um espaço e uma atividade principal específica. Ao longo do período colonial, esses movimentos sobrepuseram-se e articularam-se, somaram-se e limitaram-se, sendo conformados e conformadores de um domínio dos colonos - os paulistas, em especial - sobre essas regiões e configurando, assim, o que podemos definir como um único território.

No escopo de nossa pesquisa, denominamo-lo rede intracolonial paulista - partindo das referências precursoras, mais ou menos precisadas, ao sertão paulista. Mas entendemos essa definição de território como rede de localidades, intencionalidades, atividades e populações como um processo não exclusivo desse sertão.

Uma manifestação desse processo é a própria criação de vilas e cidades ao longo do espaço da colônia, que podiam servir a fins diversos. Para Nestor Goulart Reis Filho, tratou-se da constituição de uma "rede urbana", elaborada desde os primeiros momentos da ocupação da colônia, com a fundação de São Vicente, em I532. Essa rede era a própria conformação material da política urbanizadora levada a cabo pela Coroa portuguesa, como forma de domínio da população nativa e das terras,

54 Ibid., “Sertão”. In: Op. cit., p. 98-I72.

55 Entendemos por "país" os limites oficiais das fronteiras entre as Américas portuguesa e espanhola.

56 Ibid., p. 148 . 
ocupadas ou não por ela: "a rede urbana [...] é o conjunto das respostas às solicitações do processo".57

Um momento específico dessa política urbanizadora é o "programa de construção de vilas", ${ }^{8}$ assim definido por Roberta Marx Delson, em Novas vilas para 0 Brasil-Colônia: Planejamento Espacial e Social no Século XVIII. Nas palavras da autora,

em resposta a quatro estímulos interligados - a distribuição de terras; a descoberta de ouro; a necessidade de implantar a lei e a ordem no sertão; e a ameaça pendente dos interesses espanhóis -, os portugueses resolveram-se a cobrir a hinterlândia com um sistema de cidades, vilas e povoações organizadas. 59

Em conformidade com a hipótese de Nestor Goulart sobre a formação do território brasileiro a partir da ação sistemática da Coroa portuguesa na configuração de uma rede urbana, Delson afirma que as ações de povoamento do século XVIII foram definidas pelo caráter macroeconômico dos planos da metrópole. ${ }^{60}$ Ao definir-se mesmo que parcialmente - pelas instituições, formas materiais e limites advindos dos projetos oficiais da Coroa, o espaço da colônia transformava-se em território de seu império.

Por um lado, é preciso rememorar que as ações oficiais não dispensavam o braço particular; ao contrário, eram levadas a cabo em meio a um intrincado equilíbrio entre a submissão e o reconhecimento dos esforços dos colonos, como discutido por Laura de Mello e Souza, Maria de Fátima Gouvêa e outros. Esse processo não foi, tampouco, exclusivamente escorado nos intentos do rei.

Segundo Damião Esdras Araújo Arraes, data do século XVII a aplicação da Coroa na criação de estradas como parte de uma "empresa urbanizadora do sertão nordestino”, ${ }^{61}$ necessária por conta das dificuldades de acesso às possessões portuguesas para além de São Luiz do Maranhão, o que as tornava mais suscetíveis às investidas de outros povos europeus e mesmo à manutenção da ocupação indígena. No entanto, o próprio Arraes adverte que

Apesar dos esforços dos representantes do rei na colônia em devassar o interior do Nordeste, é somente devido à criação de gado que muitos outros caminhos seriam construídos. Inicialmente, fazendeiros, vaqueiros e tangedores (aqui poderiam ser

57 REIS, Nestor Goulart. Evolução Urbana do Brasil (I500-I720). São Paulo: Livraria Pioneira, I968, p. 78.

58 DELSON, Roberta Marx. Novas vilas para o Brasil-Colônia: planejamento espacial e social no século XVIII. Brasília: Editora Alva-Ciord, I997, p. 9.

59 Ibid., p. I4.

60 Ibid., p. 98.

6I ARRAES, Damião Esdras Araújo. Curral de reses, curral de almas: urbanização do sertão nordestino entre os séculos XVII e XIX. 20I2. Dissertação (Mestrado) - Faculdade de Arquitetura e Urbanismo, Universidade de São Paulo, São Paulo, 20I2, p. Ioo. 
homens livres, índios ou escravos) utilizavam as velhas trilhas para levar as manadas às invernadas, feiras ou portos. ${ }^{62}$

"A pecuária extensiva, economia base [do] sertão nordestino, a partir de meados dos Seiscentos, foi o integrador de uma nova unidade territorial." "33 Arraes vai além da ideia dos caminhos como ligações e remete-se à urbanização atrelada a eles: "Dessa maneira, uma rede urbana de povoações e vilas estava em franca ascensão, graças ao gado conduzido de um ponto a outro do Nordeste". ${ }^{64}$

Para a concretização dessa rede, contribuíram tanto o intento de ocupação e posse de terras, em torno do qual se uniram o Estado português e a Igreja, quanto as povoações originadas nos pousos de gado, que de fato operacionalizaram o que podemos chamar de "interiorização", transformando esse espaço num território próprio.

\section{Apontamentos finais}

Como procuramos mostrar, cada pesquisa da história colonial brasileira - ou o estudo de cada objeto - faz uso de um conceito de "território" distinto - ainda que haja sobreposições -, que busca a maior pertinência possível aos seus domínios. Para os fins de nossa pesquisa atual, conforme mencionado, mobilizamos a constituição de uma rede que se estendia majoritariamente nos sertões coloniais. Entre os seus elementos formadores, estão a política de ocupação da Coroa portuguesa, as disputas militares pela ampliação e consolidação das fronteiras com a América espanhola e as atividades econômicas em que se engajava sua população.

Em meio ao desenvolvimento desse território e à sua apreensão na historiografia brasileira e brasilianista, foram formadas interpretações hegemônicas sobre os sertões, às quais, ao longo do tempo, atribuiu-se mais ou menos valor. Não são poucos os trabalhos que se propõe a desconstruir essas imagens, como é o caso da tese de doutorado de Tiago Kramer de Oliveira, ${ }^{65}$ acerca "das práticas administrativas na legitimação da posse da terra". ${ }^{66}$

Contudo, a forma como o autor mobiliza a cartografia histórica e relaciona-a às ações, oficiais ou não, faz com que seu trabalho transborde essa temática, tocando ainda outra esfera possível de conceituação de "território", que perpassa todas as

\footnotetext{
62 Ibid., p. I03 [grifos nossos].

63 Ibid., p. I04 [grifos nossos].

64 Ibid., p. I07.

65 OLIVEIRA, Tiago Kramer de. Desconstruindo velhos mapas, revelando espacializações: a economia colonial no centro da América do Sul. 20I2. Tese (Doutorado) - Faculdade de Filosofia, Letras e Ciências Humanas, Universidade de São Paulo, São Paulo, 20I2. Vale dizer que o autor trabalha, no texto, constantemente, com os conceitos de "territorialização" e "espacialização", de modo que seria, no mínimo, prudente apresentar um conjunto de significados desses termos, a fim de estabelecer pressupostos comuns entre a tese e os leitores.

66 Ibid., p. I7.
} 
demais significações; trata-se do território como ideologia. Não dispensamos a essa hipótese um item particular, justamente pelo entendimento de que essa conceituação está presente, reconhecidamente ou não, na configuração dos estudos citados.

Destarte, Oliveira discute a própria classificação das fontes com que trabalhará - os “mapas sertanistas", assim identificados no acervo da Biblioteca Nacional do Rio de Janeiro (BNRJ). Como uma primeira entrada possível para a compreensão dessa nomenclatura, o autor remonta ao significado da palavra "sertão" em um dicionário do início do século XVIII: "região apartada do mar e por todas as partes metidas entre terras" ${ }^{\circ}$. O que essa definição aponta é a imprecisão da demarcação espacial desse território, não porque fosse impossível fazê-lo, mas porque, de certo, seus limites absolutos só poderiam ser determinados por elementos outros que não apenas as condições geográficas.

Ao problematizar a coleção escolhida, o historiador afirma que, originalmente, os "mapas sertanistas" eram, em verdade, referidos como "mapas dos sertanistas", o que denota uma relação de intencionalidade na produção desses registros. "Poderíamos afirmar que a 'cartografia do sertão' é a construção de representações sobre o espaço do sertão [...]. Com efeito, cremos, em 'mapas' que criaram o sertão"68. Partindo desse pressuposto, tanto os mapas originais quanto os estudos que os mobilizam como fontes acabam por criar e recriar o que se entende do território ali contido.

"A imagem do sertão é reveladora de pressupostos que extrapolam a análise documental, imagem que parece inquebrantável, e ainda hoje naturalizada na produção historiográfica do litoral"69. Essa imagem, no entanto, não foi constante nas representações e interpretações do espaço colonial e seus territórios. Para elucidar, ainda que de forma embrionária, as variações da conceituação do "sertão", recorreremos a nossa própria pesquisa em curso e tomaremos duas circunstâncias, distantes cerca de um século: a supramencionada produção do Mapa das Cortes e a cartografia original da província de São Paulo.

No bojo das negociações do Tratado de Madrid, o domínio paulista sobre o espaço interior da colônia foi traduzido como ocupação sólida e uso permanente daquelas terras pelos portugueses, de forma devidamente representada no sobredito mapa. A dominação e apropriação dessas áreas - mais do que isso, a devida representação

67 BLUTEAU, Raphael. Vocabulario portuguez e latino: aulico, anatomico, architectonico.... Coimbra: Collegio das Artes da Companhia de Jesus, I7I2-I728, v. 7, p. 6I3. Apud OLIVEIRA, op. cit., p. 22.

68 Ibid., p. 29.

69 Ibid., p. 57. Oliveira faz extensa e indispensável ponderação sobre o caráter legitimador da cartografia, de modo geral, e principalmente do uso de recursos computadorizados, tais como programas SIG, que podem deslocar a problematização, a investigação e a formulação de hipóteses para um segundo plano, encobertas pela persuasão das novas formas de representação, tidas como objetivas e confiáveis - traduções verdadeiras das informações históricas, de outra forma pouco decifráveis. Ibid., p. 6I-68. Para uma sistematização das relações entre a computação e a pesquisa histórica, ver SANTOS, Amália Cristóvão dos. Os desenvolvimentos tecnológicos e o uso de suas ferramentas na reprodução e manipulação da cartografia histórica. In: III ENANPARQ ARQUITETURA, CIDADE E PROJETO, 20I4, São Paulo. Anais do III ENANPARQ.... São Paulo: Universidade Presbiteriana Mackenzie; Campinas: Pontifícia Universidade Católica de Campinas, 20I4. I CD-ROM. 
dessas características - foram expedientes decisivos para o sucesso do acordo de sua posse oficial pelo império português.

O caráter central e estratégico dessa representação pode ser aferido pela comparação entre o nível pretendido e representado de detalhamento dos confins coloniais no Mapa das Cortes e a indicação da existência de áreas classificadas como desconhecidas no primeiro mapa provincial de São Paulo, editado em I837, pelo engenheiro Daniel Pedro Müller, no ensejo da preparação de seu Ensaio d'um quadro estatístico da província de São Paulo, ${ }^{70}$ publicado no ano seguinte.

No referido conjunto, certas áreas paulistas foram classificadas como "sertão desconhecido", não por serem de fato inexploradas, mas por terem configurações tais que as tornavam indesejáveis para os rumos pretendidos para a província. Essa denominação cumpria, pois, a função de legitimar a implantação de novas formas produtivas e de ocupação dessas terras, mais afins aos planos econômicos e políticos da elite dirigente de São Paulo.

Entre essas duas vistas do "sertão", vale lembrar, está em andamento um processo de "autoenobrecimento" dos bárbaros sertanistas. Para Laura de Mello e Souza, a forma encontrada pelos próprios paulistas para desfazerem-se do dualismo e, principalmente, das imagens de homens vis e desleais foi o forjamento de uma nobreza, desde o século XVIII, quando a capitania perde sua autonomia, e a declaração de nobreza é o "mito disponível para usos ideológicos"’ঙ.

Para o bom resultado desse processo, podemos crer que era indispensável expurgar não apenas o que havia de sertanista nesses homens, mas o próprio caráter sertanejo do espaço da capitania e posteriormente província de São Paulo. Assim, no início do século XIX, o território oficial paulista vai sendo adequado ao desenvolvimento econômico pretendido, para o qual a ideia do sertão selvagem em simbiose com os paulistas não era mais interessante. O sertão, antes dominado, era agora declarado desconhecido dos habitantes planaltinos.

Dessa forma, amarram-se, numa espécie de espiral: os mapas, produtos muitas vezes de pessoas externas ao espaço representado, reunindo informações de fontes diversas e, na história colonial do Brasil, centrados nos interesses reais; as câmaras e demais instituições da administração portuguesa no espaço colonial, em que tomavam lugar os "homens bons" e a elite local72; as dinâmicas internas que atravessavam os limites oficiais, em atividades nas quais se envolviam não apenas os grupos dirigentes mas também os demais, incluindo forros, livre e pobres, nativos, mulheres e outros; e as redes territoriais, como espaços que iam renegociando fronteiras e relações, no equilíbrio da hierarquia oficial.

70 A obra pretendia cumprir uma "descripção d'um paiz, e em particular de sua administração, população, commercio, industria, e producção; pode-se-lhe chamar - um inventario exacto do paiz”. MÜLLER, Daniel Pedro. Ensaio d'um quadro estatístico da província de São Paulo, 3 ed. São Paulo: Governo do Estado, I978 [I938], p. XXV. 7 I SOUZA, op. cit., p. I45.

72 BOXER, op. cit., p. 286. 
AMÁLIA CRISTOVÃO DOS SANTOS é doutoranda do programa de pós-graduação da Faculdade de Arquitetura e Urbanismo da Universidade de São Paulo (FAU-USP). Graduada pela Faculdade de Arquitetura e Urbanismo da Universidade de São Paulo, concluída em 2008, com a apresentação do trabalho final A Colonização e as Cidades à Brasileira: Aspectos sociológicos da urbanização. Entre 2005 e 2009, integrou o grupo de pesquisa "Pioneiros da Habitação Social no Brasil” coordenado pelos professores doutores Ana Paula Koury e Nabil Georges Bonduki. Mestrado concluído pela Faculdade de Arquitetura e Urbanismo da Universidade de São Paulo (20IO-20I3), sob orientação da professora doutora Ana Lúcia Duarte Lanna e com financiamento da Fapesp, com título Em obras: os trabalhadores da cidade de São Paulo entre I775 e I809, em processo de publicação pela Editora Alameda. Pesquisou as relações sociais e a produção do espaço urbano por trabalhadores e envolvidos em obras públicas na cidade. Doutorado em andamento pela mesma instituição e com a mesma orientadora, também com financiamento da Fapesp, iniciado em 20I4, com título Trocas e caminhos da rede intracolonial paulista em fins do século XVIII, em que pesquisa a formação do território no período colonial por meio das atividades comerciais, militares e urbanizadoras desempenhadas no período. 


\section{REFERÊNCIAS BIBLIOGRÁFICAS}

ABREU, João Capistrano Honório de. Capítulos de História Colonial. Rio de Janeiro: Civilização Brasileira, I976.

ARRAES, Damião Esdras Araújo. Curral de reses, curral de almas: urbanização do sertão nordestino entre os séculos XVII e XIX. 20I2. Dissertação (Mestrado) - Faculdade de Arquitetura e Urbanismo, Universidade de São Paulo, São Paulo, 2012.

BLAJ, llana. A trama das tensões: o processo de mercantilização de São Paulo colonial (I68I-I72I). São Paulo: Humanitas; Fapesp, 2002.

BICALHO, Maria Fernanda; FURTADO, Júnia Ferreiraa; SOUZA, Laura de Mello e. O governo dos povos. São Paulo: Alameda, 2009.

BORREGO, Maria Aparecida de Menezes A teia mercantil: negócios e poderes em São Paulo colonial (I7II-I765). São Paulo: Alameda, 2010.

BOXER, Charles. O império marítimo português I4I5-I825. São Paulo: Companhia das Letras, 2002.

BRUNO, Hernani da Silva. História e tradições da cidade de São Paulo: Volume I - Arraial de Sertanistas (I554-I828). São Paulo: Editora Hucitec, I99I.

BUENO, Beatriz Piccolotto Siqueira. Decifrando mapas: sobre o conceito de "território" e suas vinculações com a cartografia. Anais do Museu Paulista, São Paulo, v. I2, p. I93-234, jan./dez., 2004.

CINTRA, Jorge Pimentel; FURTADO, Júnia Ferreira A Carte de l’Amérique Méridionale de Bourguignon D’Anville: eixo perspectivo de uma cartografia amazônica comparada. Revista Brasileira de História, São Paulo, v. 3I, n. 62, p. 273-3I6, 20 II.

CORTESÃO, Jaime. Alexandre de Gusmão e o Tratado de Madrid, tomo 2. São Paulo: Imprensa Oficial; Fundação Alexandre de Gusmão, 2006.

DELSON, Roberta Marx. Novas vilas para o Brasil-Colônia: planejamento espacial e social no século XVIII. Brasília: Editora Alva/Ciord, I997.

FERREIRA, Mário Clemente. O Mapa das Cortes e o Tratado de Madrid: a cartografia a serviço da diplomacia. Varia História, Belo Horizonte, v. 23, n. 37, p. 5I-69, jan./jun., 2007.

. Os demarcadores do Tratado de Madrid (I750) e as reformas pombalinas de ensino. In: IV SIMPÓSIO LUSOBRASILEIRO DE CARTOGRAFIA HISTÓRICA, 20II, Porto. Anais do IV Simpósio.... Porto: Faculdade de Letras da Universidade do Porto, 20II, p. I-II.

FRAGOSO, João; GOUVÊA, Maria de Fátima Silva. Na trama das redes: política e negócios no império português, séculos XVI-XVIII. Rio de Janeiro: Civilização Brasileira, 2010.

FRAGOSO, João; GOUVÊA, Maria de Fátima Silva; BICALHO, Maria Fernanda Baptista. Uma leitura do Brasil colonial: Bases da materialidade e da governabilidade no Império. Penélope, Lisboa, n. 23, 2000, p. 67-88.

FONSECA, Cláudia Damasceno. Arraiais e vila d'El Rei: espaço e poder nas minas setecentistas. Belo Horizonte: Editora UFMG, $20 I I$.

. Retóricas cartográficas: as vilas e seus territórios nas Minas setecentistas. In: $3^{\circ}$ SIMPÓSIO IBEROAMERICANO DE HISTÓRIA DA CARTOGRAFIA - Agendas para História da Cartografia Iberoamericana, 20Io, São Paulo. Disponível: <http://3siahc.files.wordpress.com/20Io/o4/claudiadamasceno-3siach-20Io.pdf $>$. Acesso em: I6 Jan. 20I4.

GIRARDI, Gisele. Leitura de mitos em mapas: um caminho para repensar as relações entre geografia e cartografia. Geografares, Vitória, v. I, n. I, p. 4I-50, jun., 2000.

HOLANDA, Sérgio Buarque de. Movimentos da população em São Paulo no século XVIII. Revista do Instituto de Estudos Brasileiros, São Paulo, v. I, p. 55-III, I966. 
. Caminhos e Fronteiras. São Paulo: Cia. das Letras, I994.

KANTOR, Iris. Cartografia e diplomacia: usos geopolíticos da informação toponímica (I750-I850). Anais do Museu Paulista, São Paulo, v. I7, n. 2, p. 39-6I, jul./dez., 2009. Disponível em: <http://www.scielo. br/pdf/anaismp/vi7n2/o4.pdf >. Acesso em: 6 Ago. 2013.

MARANHO, Milena Fernandes. O moinho e o engenho. 2006. Tese (Doutorado) - Faculdade de Filosofia, Letras e Ciências Humanas, Universidade de São Paulo, São Paulo, 2006.

MARX, Murillo. Nosso chão: do sagrado ao profano. São Paulo: Editora da Universidade de São Paulo, I989. MONBEIG, Pierre. Formação Histórica de São Paulo: de comunidade a metrópole. Tradução dos acréscimos Antonio Candido e Maria Sylvia Carvalho Moreira. São Paulo: Difel, I970.

OLIVEIRA, Tiago Kramer de. Desconstruindo velhos mapas, revelando espacializações: a economia colonial no centro da América do Sul. 20I2. Tese (Doutorado) - Faculdade de Filosofia, Letras e Ciências Humanas, Universidade de São Paulo, São Paulo, 2012.

PRADO Jr., Caio. O fator geográfico na formação e no desenvolvimento da cidade de São Paulo. In:

Cidade de São Paulo: Geografia e História. São Paulo: Brasiliense, I989.

PRADO, Paulo. Paulística etc. São Paulo: Cia. das Letras, 2004.

REIS, Nestor Goulart. Evolução Urbana do Brasil (I500-I720). São Paulo: Livraria Pioneira, I968.

SANTOS, Amália Cristóvão dos. Os desenvolvimentos tecnológicos e o uso de suas ferramentas na reprodução e manipulação da cartografia histórica. In: III ENANPARQ - ARQUITETURA, CIDADE E PROJETO, 20I4, São Paulo. Anais do III ENANPARQ.... São Paulo: Universidade Presbiteriana Mackenzie; Campinas: Pontifícia Universidade Católica de Campinas, 20I4. I CD-ROM.

. Em obras: os trabalhadores da cidade de São Paulo entre I775 e I809. São Paulo: Alameda, 2015 [no prelo].

SOUZA, Laura de Mello e. O Sol e a Sombra. São Paulo: Companhia das Letras, 2006.

VIDAL, Laurent. Mazagão, a cidade que atravessou o Atlântico: do Marrocos à Amazônia (I769-I783). São Paulo: Martins, 2009.

VILLA, Marco Antonio. Breve história do Estado de São Paulo. São Paulo: Imprensa Oficial, 2010. 